\title{
Design and Experimental Results of Battery Charging System for Microgrid System
}

\author{
Byunggyu Yu \\ Division of Electrical, Electronics and Control Engineering, Kongju National University, Chungcheongnam-do, Republic of Korea \\ Correspondence should be addressed to Byunggyu Yu; bgyuyu@kongju.ac.kr
}

Received 26 July 2016; Accepted 11 October 2016

Academic Editor: Santolo Meo

Copyright (C) 2016 Byunggyu Yu. This is an open access article distributed under the Creative Commons Attribution License, which permits unrestricted use, distribution, and reproduction in any medium, provided the original work is properly cited.

\begin{abstract}
Nowadays, many countries have paid attention to renewable energy due to fossil fuel crisis and its related environmental pollution. In particular, following the government supply business for renewable energy industry, the private sectors drive the stable power supply by using renewable sources for both microgrid system and standalone application. Battery charging and discharging control system of microgrid system are critical to extend lifetime of standalone photovoltaic system. Corresponding to this demand, this paper presents the development of battery charging and discharging system based on battery modeling, SOC (state of charge) estimation, and its implementation for $5 \mathrm{~kW}$. As a result, the conversion efficiency shows $96.35 \%$ with over $95 \%$ charging performance.
\end{abstract}

\section{Introduction}

A microgrid system is defined as an autonomous energy grid system to operate in parallel with or independently of the traditional grid $[1,2]$. In accordance with the growing industry trend on renewable energy, microgrid systems integrated with renewable energy resources are becoming widespread in the world [3-5]. This type of microgrid system consisted of several renewable energy resources like photovoltaic generation and a battery backup system like lead-acid battery system [6-8]. In particular, battery system is the key component to stabilize the microgrid system as a concrete grid voltage function. Typically, lead-acid battery is mostly used for storage system, but it has relative short lifetime for a stable operation. Thus, the battery charging and discharging system are regarded as one of the most essential systems for the long lifetime operation [9-12]. The battery systems for both microgrid system and standalone PV generation are different from the conventional system for UPS (uninterruptable power supply), because the charging and discharging profiles are depending on the environmental condition like irradiance. Corresponding to this demand, this paper presents the development of battery charging and discharging system based on battery modeling, SOC (state of charge) estimation, and its implementation.

This paper consisted of three sections. Firstly, the modelling of battery and battery charger/discharger is presented. Secondly, based on the modeling, the simulation of the target system is conducted with topology design for $5 \mathrm{~kW}$. Lastly, with the proposed control algorithm, the final system output is implemented to verify the proposed algorithm and hardware.

\section{Battery Modeling}

It is required to have appropriate battery modeling to implement a battery charging and discharging system. Typically, this modeling can be classified into three categories. One is an electrochemical modeling, and it is too complicated to apply even though it shows the highest accuracy [13]. The second one is a mathematical modeling and it is acceptable to apply under some limited condition [14]. The third one is based on the electrical modeling by using voltage source, resistor, and capacity and it is practical for battery charging system implementation. In particular, this paper uses the electrical modeling for battery as in Figure 1. In order to model battery 


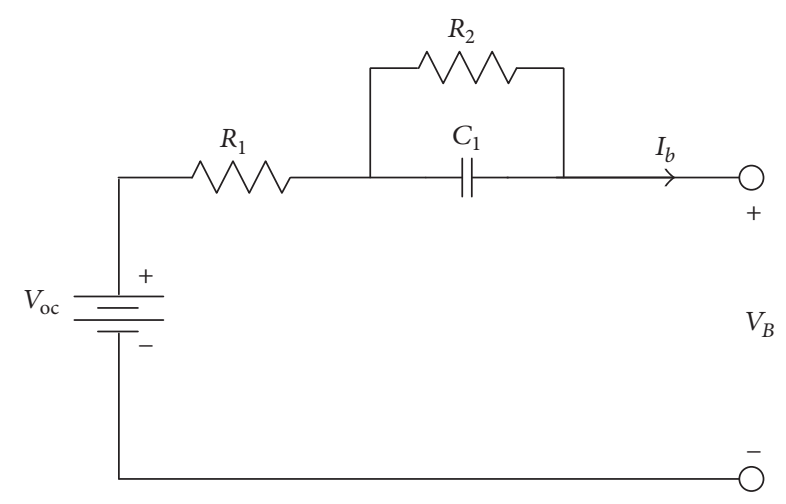

FiguRE 1: Battery electrical modeling.

electrical characteristic, it is assumed that SOC function is used to improve the modeling accuracy as the following equation:

$$
\mathrm{SOC}=\frac{\text { Ah_init }-\int\left(I_{\text {battery }_{\text {out }}}\right) d t}{\text { Ah_rate }}
$$

where Ah_rate is the battery rating and Ah_init is the initial battery charging state.

\section{System Configuration}

Battery system is installed to regulate the DC bus among PV generation, wind turbine, and local loads in Figure 2. Specifically, the battery charger is implemented by using $5 \mathrm{~kW}$ bidirectional buck-boost converter. As shown in Figure 3, the operating mode between charging mode and discharging mode is determined by monitoring DC bus voltage and current. In other words, when it is the charging mode, the charger is operated as buck converter. While it is the other mode, the charger is operated as the boost converter.

3.1. Buck Converter for Charging Mode. Buck converter is called a step-down converter, at which the input voltage magnitude $v_{1}$ is decreased from the output voltage $v_{2}$ by the on/off control of switch $S_{1}$ (Figure $4(\mathrm{a})$ ). When the switch $S_{1}$ is on during $D T$, where the switching duty ratio is $D$ and the switching period is designated as $T$, the inductor voltage $v_{L}$ is determined by the following equation. During the short switching period $T$, both $v_{1}$ and $v_{2}$ are assumed as constant values.

$$
\begin{aligned}
v_{L} & =v_{1}-v_{2}=L \frac{d i_{L}}{d t}, \\
\frac{d i_{L}}{d t} & =\frac{\Delta i_{L}}{\Delta t}=\frac{v_{1}-v_{2}}{L}, \\
\left(\Delta i_{L}\right)_{\text {on }} & =\left(\frac{v_{1}-v_{2}}{L}\right) D T .
\end{aligned}
$$

When the switch $S_{1}$ is off during $(1-D) T$, the inductor voltage $v_{L}$ is determined by the following equation.

$$
\begin{aligned}
v_{L} & =-v_{2}=L \frac{d i_{L}}{d t}, \\
\frac{d i_{L}}{d t} & =\frac{\Delta i_{L}}{\Delta t}=\frac{-v_{2}}{L}, \\
\left(\Delta i_{L}\right)_{\text {off }} & =\left(\frac{-v_{2}}{L}\right)(1-D) T .
\end{aligned}
$$

Under the steady state condition for the continuous current control, the net inductor current change during one switching cycle is equal to zero as following equation.

$$
\begin{aligned}
\left(\Delta i_{L}\right)_{\text {on }}+\left(\Delta i_{L}\right)_{\text {off }} & =0 \\
v_{2} & =D v_{1} .
\end{aligned}
$$

Thus, the output voltage $v_{2}$ is equal to $D v_{1}$.

Since the average capacitor $\left(C_{2}\right)$ current is equal to zero at the steady state, the average inductor current should be equal to the load current. $R$ is representing the load resistance for the $5 \mathrm{~kW}$ battery charger converter. Since the nominal battery bank voltage is $240 \mathrm{~V}$, the nominal load resistance can be calculated by the power definition. This is because the load current through $R$ is limited by the controller. Thus, $R$ is used for the converter design. Thus,

$$
I_{L}=I_{R}=\frac{v_{2}}{R} .
$$

The maximum inductor current and the minimum inductor current can be calculated from the inductor average current and the net inductor current change.

$$
\begin{aligned}
& I_{L, \text { max }}=I_{L}+\frac{\Delta i_{L}}{2}, \\
& I_{L, \text { min }}=I_{L}-\frac{\Delta i_{L}}{2} .
\end{aligned}
$$

For the continuous current mode of inductor current, the minimum inductor current $I_{L \text {,min }}$ should be more than zero. Thus, the minimum inductance can be calculated from the fixed switching frequency $f$.

$$
L_{\min }=\frac{(1-D) R}{2 f} .
$$

From the designed switching $12 \mathrm{kHz}$ and $5 \mathrm{~kW}$ converter power capacity, the minimum inductance $L_{\min }$ can be calculated by $877 \mathrm{uH}$.

For the capacitance design, the capacitance $C_{2}$ can be calculated by the designed voltage ripple ratio.

$$
\begin{aligned}
& \Delta Q=C_{2} \Delta v_{2}, \\
& \Delta Q=\frac{1}{2} \frac{T}{2} \frac{\Delta i_{L}}{2}=\frac{T \Delta i_{L}}{8} .
\end{aligned}
$$

When the current variation is $40 \%$ and the ripple voltage $\Delta v_{2}$ is designed as $1 \mathrm{~V}$, the designed capacitance $C_{2}$ can be designed as $87.5 \mathrm{uF}$. 

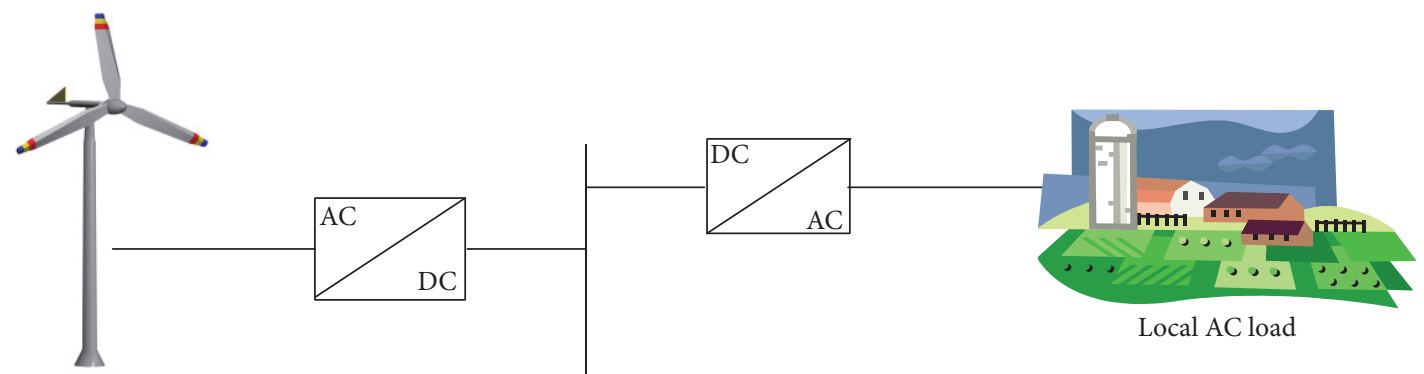

Wind turbine

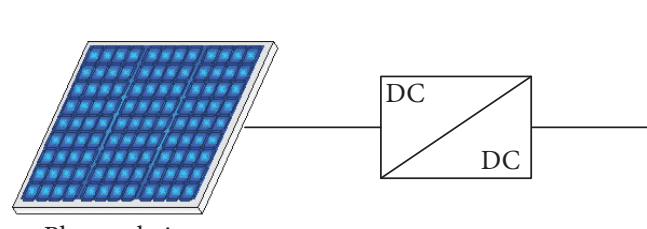

Photovoltaic

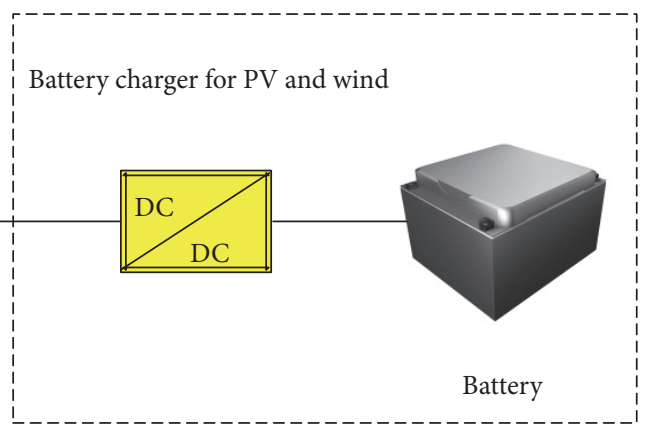

Research target

FIGURE 2: Standalone micropower grid configuration.

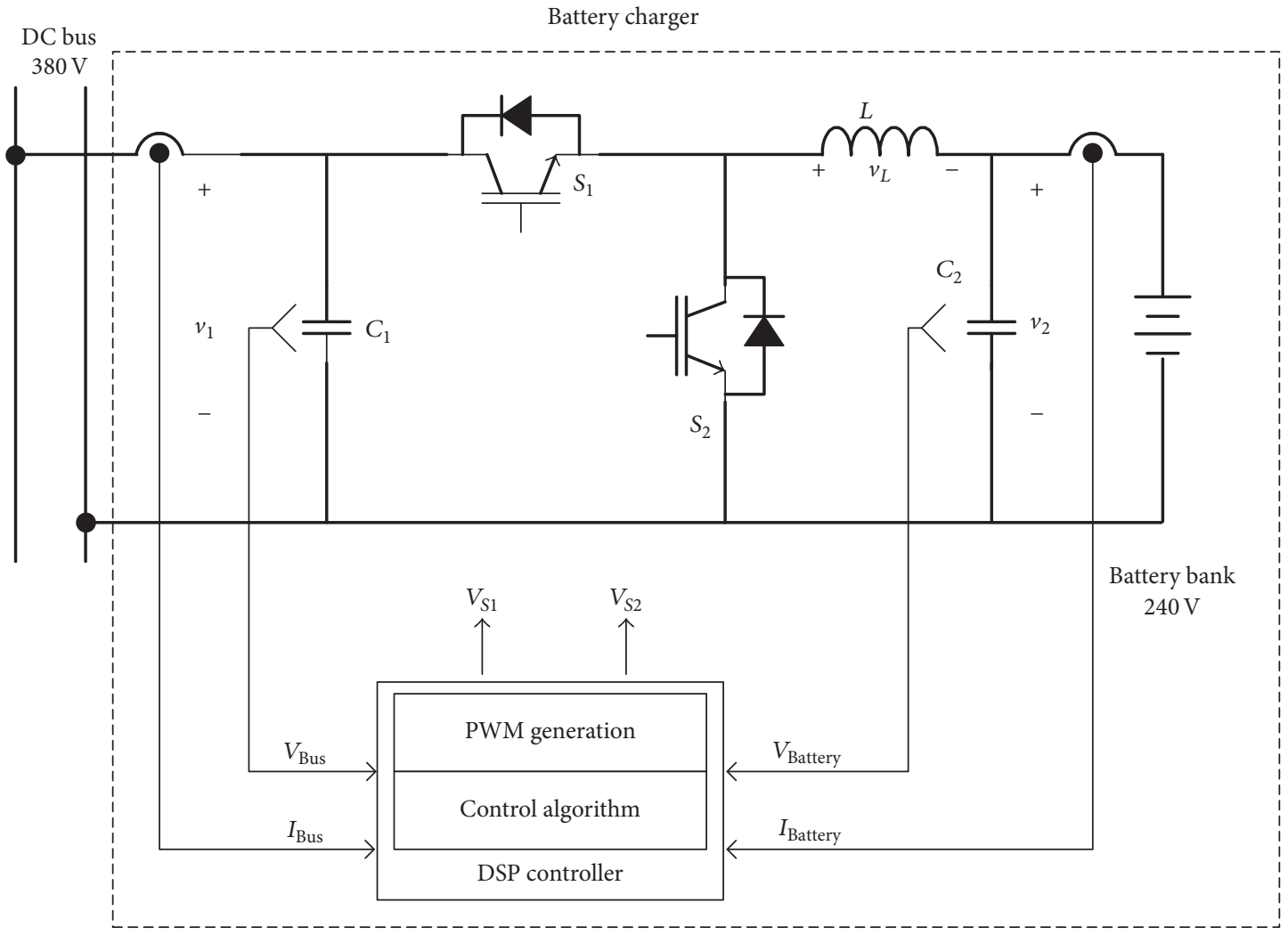

Figure 3: Battery charger system diagram. 


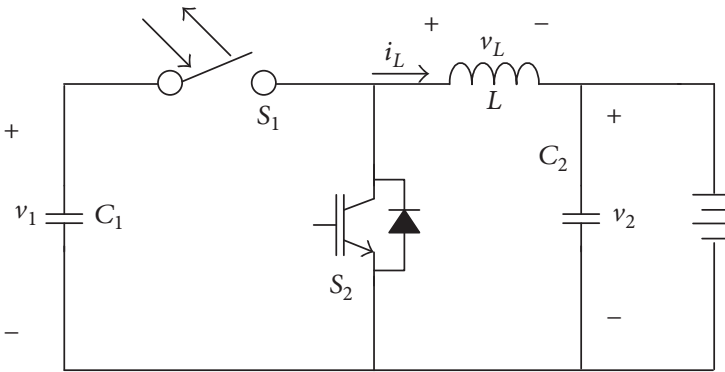

(a)

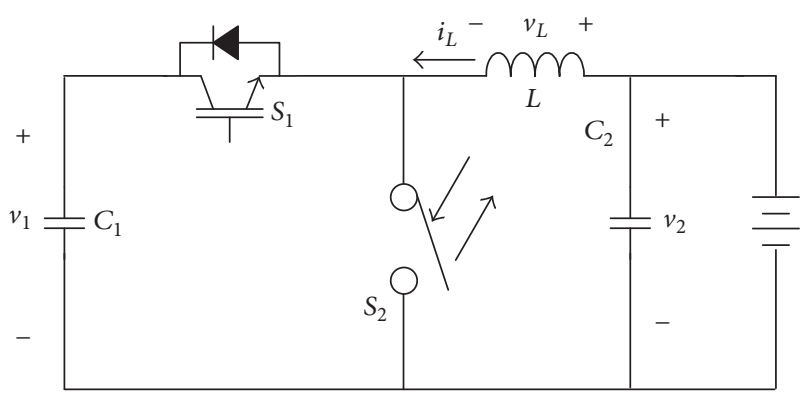

(b)

FIGURE 4: Battery charger operational circuit diagram. (a) Buck converter for charging mode; (b) boost converter for discharging mode.

3.2. Boost Converter for Discharging Mode. Boost converter is called a step-up converter, at which the input voltage magnitude $v_{2}$ is decreased from the output voltage $v_{1}$ by the on/off control of switch $S_{2}$ (Figure 4(b)). When the switch $S_{2}$ is on during $D T$, where the switching duty ratio is $D$ and the switching period is designated as $T$, the inductor voltage $v_{L}$ is determined by the following equation.

$$
\begin{aligned}
v_{L} & =v_{2}=L \frac{d i_{L}}{d t}, \\
\frac{\Delta i_{L}}{\Delta t} & =\frac{\Delta i_{L}}{D T}=\frac{v_{2}}{L}, \\
\left(\Delta i_{L}\right)_{\text {on }} & =\left(\frac{v_{2}}{L}\right) D T .
\end{aligned}
$$

When the switch $S_{1}$ is off during $(1-D) T$, the inductor voltage $v_{L}$ is determined by the following equation.

$$
\begin{aligned}
v_{L} & =v_{2}-v_{1}=L \frac{d i_{L}}{d t}, \\
\frac{d i_{L}}{d t} & =\frac{\Delta i_{L}}{\Delta t}=\frac{v_{2}-v_{1}}{L}, \\
\left(\Delta i_{L}\right)_{\mathrm{off}} & =\left(\frac{v_{2}-v_{1}}{L}\right)(1-D) T .
\end{aligned}
$$

Under the steady state condition for the continuous current control, the net inductor current change during one switching cycle is equal to zero as following equation.

$$
\begin{aligned}
\left(\Delta i_{L}\right)_{\text {on }}+\left(\Delta i_{L}\right)_{\text {off }} & =0 \\
v_{1} & =\frac{v_{2}}{1-D} .
\end{aligned}
$$

Thus, the output voltage $v_{1}$ is equal to $v_{2} /(1-D)$.

Since the average capacitor $\left(C_{1}\right)$ current is equal to zero at the steady state, the average inductor current should be equal to the load current. Thus,

$$
I_{L}=I_{R}=\frac{v_{1}}{R}=\frac{v_{2}}{(1-D)^{2} R} .
$$

The maximum inductor current and the minimum inductor current can be calculated from the inductor average current and the net inductor current change.

$$
\begin{aligned}
& I_{L, \text { max }}=I_{L}+\frac{\Delta i_{L}}{2}, \\
& I_{L, \text { min }}=I_{L}-\frac{\Delta i_{L}}{2} .
\end{aligned}
$$

For the continuous current mode of inductor current, the minimum inductor current $I_{L \text {,min }}$ should be more than zero. Thus, the minimum inductance $L$ can be calculated from the fixed switching frequency $f$.

$$
L_{\min }=\frac{D(1-D)^{2} R}{2 f} .
$$

From the designed switching $12 \mathrm{kHz}$ and $5 \mathrm{~kW}$ converter power capacity, the minimum inductance $L_{\min }$ can be calculated by $884 \mathrm{uH}$.

For the capacitance design, the capacitance $C_{2}$ can be calculated by the designed voltage ripple ratio.

$$
\begin{aligned}
& \Delta Q=C_{1} \Delta v_{1}, \\
& \Delta Q=\frac{v_{1}}{R} D T .
\end{aligned}
$$

When the ripple voltage $\Delta v_{1}$ is designed as $1 \mathrm{~V}$, the designed capacitance $C_{1}$ from (8) can be designed as $400 \mathrm{uF}$.

\section{Experimental Results}

The proposed battery charging system was implemented by using buck converter as designed in the previous section. The electrical specification is listed in Table 1. Figure 5 shows the implemented system front-view.

Figure 6 shows the experimental waveforms for both CC and CV modes. DC link voltage is implemented by DC power supply and batteries are stacked to generate $240 \mathrm{~V}$. Buck-boost converter is implemented for battery charging operation. The charging current is designed as $3 \mathrm{~A}$, while the maximum charging current is limited as $10 \mathrm{~A}$, and the temperature is controlled to be less than $50^{\circ} \mathrm{C}$. When the battery voltage reaches the nominal battery voltage, the charging mode 


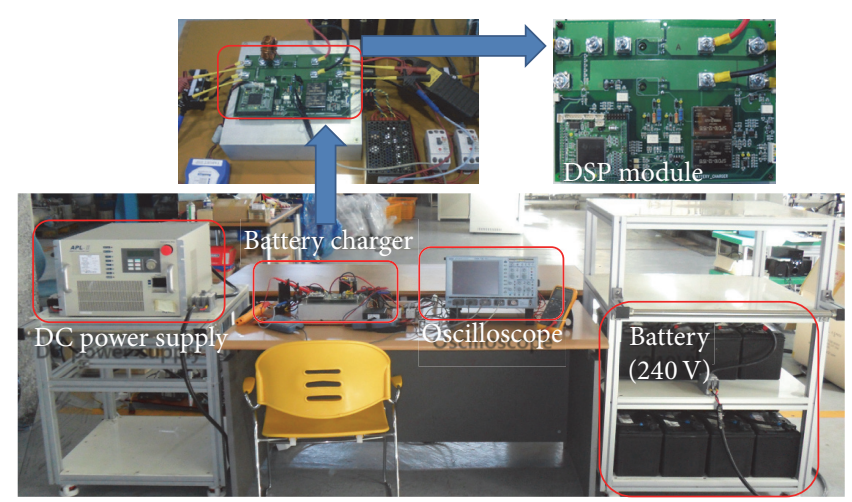

FIGURE 5: System hardware front-view picture.

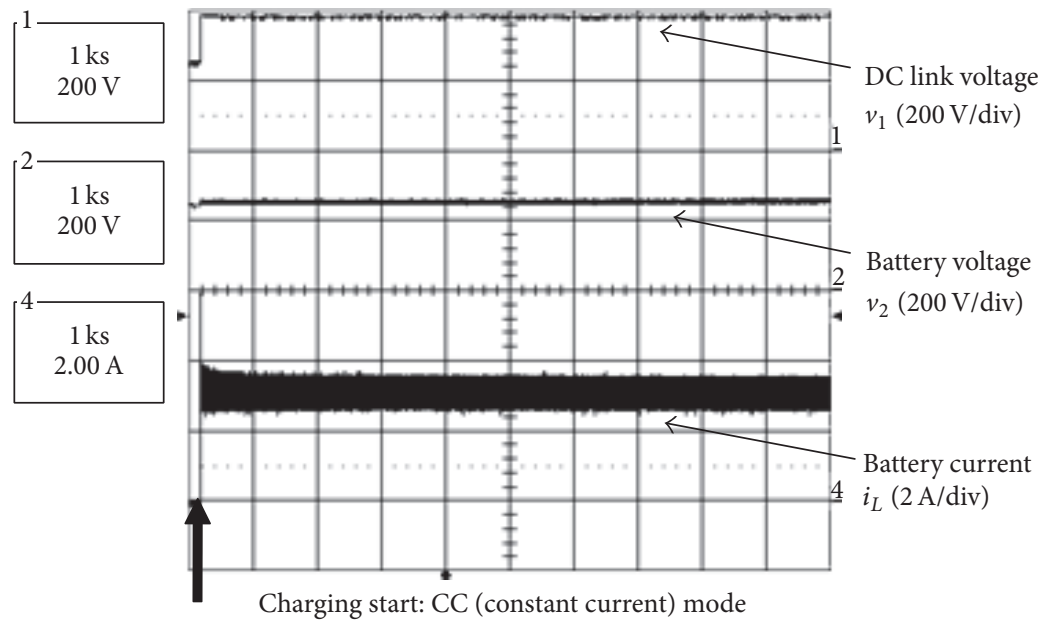

(a)

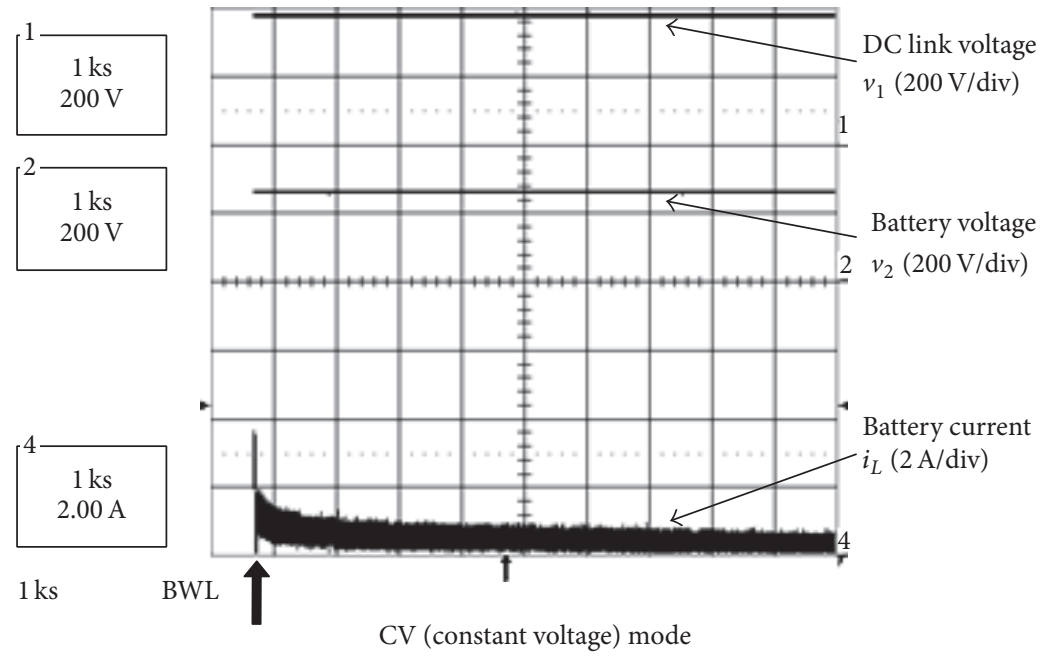

(b)

FIGURE 6: Experimental result for battery charging performance. (a) CC mode; (b) CV mode.

moves from constant current (CC) mode to constant voltage (CV) mode as shown in Figure 6. As a result, SOC as a charging performance index, is estimated over $95 \%$ with 96.35 conversion efficiency.

\section{Conclusion}

This paper presents the development of battery charging and discharging system based on battery modeling, SOC 
TABLE 1: Electrical specification.

\begin{tabular}{lc}
\hline Item & Value \\
\hline Bus voltage $\left(v_{1}\right)$ & $380 \mathrm{~V}$ \\
Nominal battery voltage $\left(v_{2}\right)$ & $240 \mathrm{~V}$ \\
Rated power capacity $(P)$ & $5 \mathrm{~kW}$ \\
Inductance $(L)$ & $880 \mathrm{uH}$ \\
Bus capacitance $\left(C_{1}\right)$ & $400 \mathrm{uF}$ \\
Battery capacitance $\left(C_{2}\right)$ & $94 \mathrm{uF}$ \\
Switching frequency $(f)$ & $12 \mathrm{kHz}$ \\
\hline
\end{tabular}

estimation, and its implementation. As a result, the conversion efficiency shows $96.35 \%$ with over $95 \%$ charging performance. Based on the presented design and experimental results for battery charging system, the battery backup system can be expected to be of high efficiency with long lifetime.

\section{Competing Interests}

The author declares no competing interests.

\section{Acknowledgments}

This work was supported by the National Research Foundation of Korea (NRF) Grant funded by the Korea Government (MSIP) (no. 2016R1C1B1007001).

\section{References}

[1] O. Deblecker, C. Stevanoni, and F. Vallee, "Cooperative control of multi-functional inverters for renewable energy integration and power quality compensation in micro-grids," in Proceedings of the International Symposium on Power Electronics, Electrical Drives, Automation and Motion (SPEEDAM '16), pp. 1051-1058, Capri, Italy, June 2016.

[2] F. Ornelas-Tellez, "Optimal control for a renewable-energybased micro-grid," in Proceedings of the IEEE International Autumn Meeting on Power, Electronics and Computing (ROPEC '14), pp. 1-6, November 2014.

[3] J. Dong, F. Gao, X. Guan, Q. Zhai, and J. Wu, "Storage-reserve sizing with qualified reliability for connected high renewable penetration micro-grid," IEEE Transactions on Sustainable Energy, vol. 7, no. 2, pp. 732-743, 2016.

[4] L. Chen and S. Mei, "An integrated control and protection system for photovoltaic microgrids," CSEE Journal of Power and Energy Systems, vol. 1, no. 1, pp. 36-42, 2015.

[5] T. Strasser, F. Andrén, J. Kathan et al., "A review of architectures and concepts for intelligence in future electric energy systems," IEEE Transactions on Industrial Electronics, vol. 62, no. 4, pp. 2424-2438, 2015.

[6] N. Fernanders, R. Demonti, J. Andrade et al., "Control strategy for pulsed lead acid battery charger for stand alone photovoltaics," in Proceedings of the IEEE 13th Brazilian Power Electronics Conference and 1st Southern Power Electronics Conference (COBEP/SPEC '15), pp. 1-6, Fortaleza, Brazil, December 2015.

[7] Y.-D. Lee, S.-Y. Park, and S.-B. Han, "Online embedded impedance measurement using high-power battery charger," IEEE Transactions on Industry Applications, vol. 51, no. 1, pp. 498-508, 2015.
[8] M. Ryu, D. Jung, J. Baek, and H. Kim, "An optimized design of bi-directional dual active bridge converter for low voltage battery charger," in Proceedings of the 16th International Power Electronics and Motion Control Conference and Exposition (PEMC '14), pp. 177-183, September 2014.

[9] R. K. Singh and S. Mishra, "A digital optimal battery charger with the inbuilt fault detection property," in Proceedings of the IEEE International Conference on Power Electronics, Drives and Energy Systems (PEDES '12), pp. 1-6, IEEE, Bengaluru, India, December 2012.

[10] Y.-L. Ke, Y.-C. Chuang, M.-S. Kang, Y.-K. Wu, C.-M. Lai, and C.-C. Yu, "Solar power battery charger with a parallel-load resonant converter," in Proceedings of the 2011 46th IEEE Industry Applications Society Annual Meeting (IAS '11), pp. 1-8, Orlando, Fla, USA, October 2011.

[11] J.-H. Lee, J.-S. Moon, Y.-S. Lee, Y.-R. Kim, and C.-Y. Won, "Fast charging technique for EV battery charger using three-phase AC-DC boost converter," in Proceedings of the 37th Annual Conference of the IEEE Industrial Electronics Society (IECON '11), pp. 4577-4582, Melbourne, Australia, November 2011.

[12] I.-S. Kim, P.-S. Ji, U.-D. Han, C.-G. Lhee, and H.-G. Kim, "State estimator design for solar battery charger," in Proceedings of the IEEE International Conference on Industrial Technology (ICIT '09), pp. 1-6, February 2009.

[13] X. Li, M. Xiao, K. Malinowski, and S.-Y. Choe, "State-of-charge (SOC) estimation based on reduced order of electrochemical model for a pouch type high power Li-polymer battery," in Proceedings of the 7th IEEE Vehicle Power and Propulsion Conference (VPPC '11), pp. 1-6, Chicago, Ill, USA, September 2011.

[14] S. Li and B. Ke, "Study of battery modeling using mathematical and circuit oriented approaches," in Proceedings of the IEEE Power and Energy Society General Meeting, pp. 1-8, Detroit, Mich, USA, July 2011. 

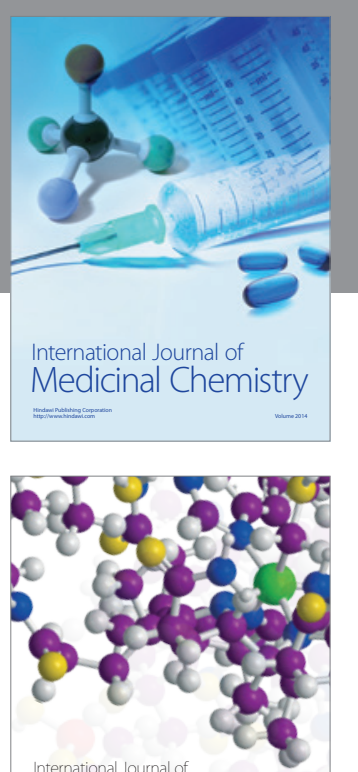

Carbohydrate Chemistry

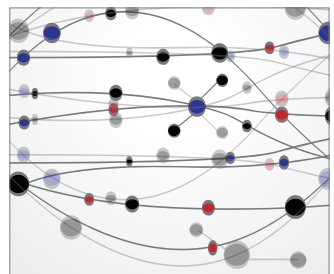

The Scientific World Journal
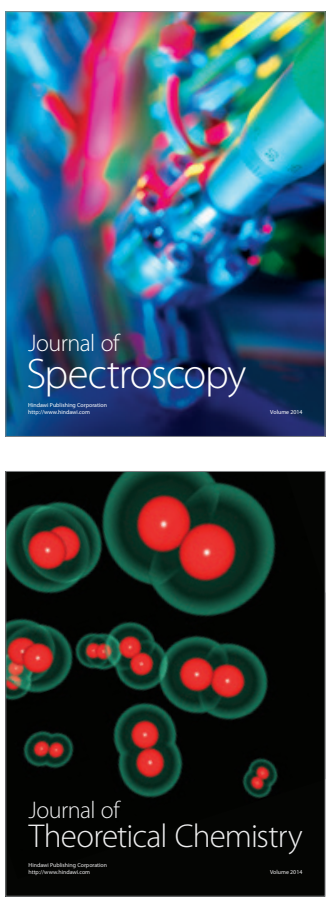
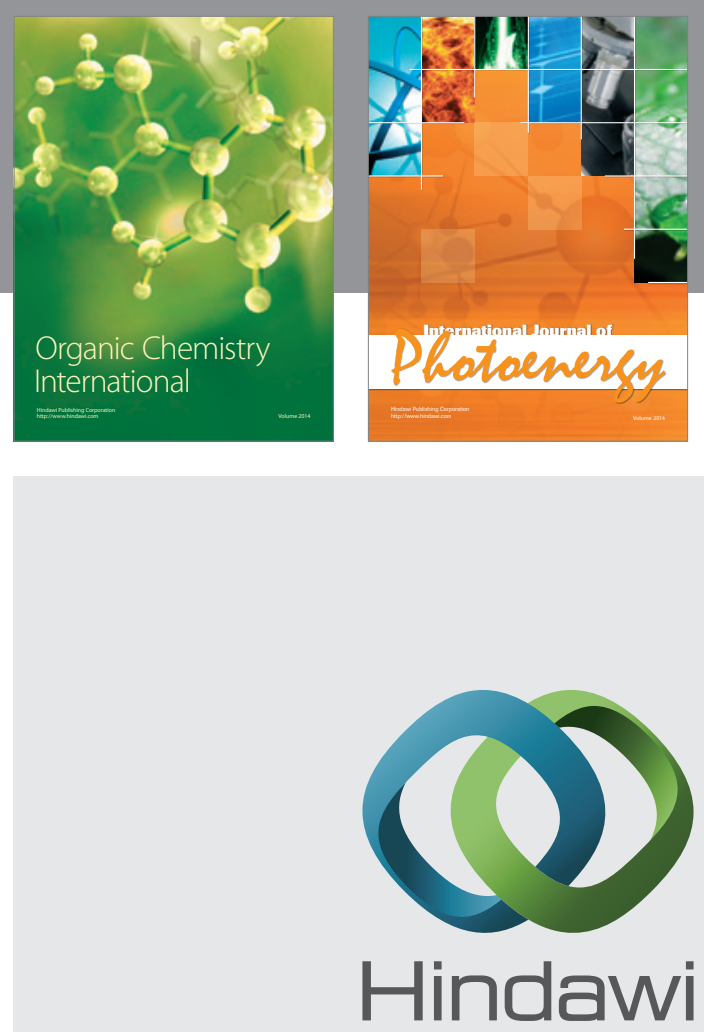

Submit your manuscripts at

http://www.hindawi.com

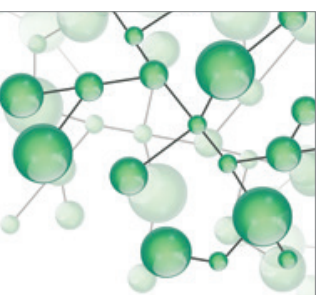

International Journal of

Inorganic Chemistry

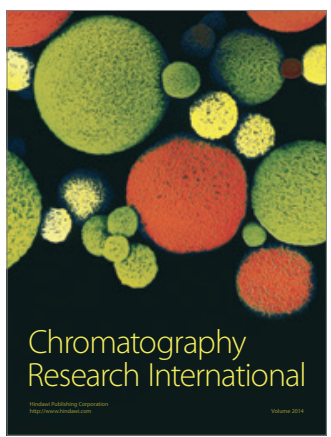

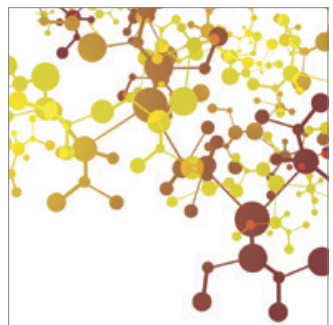

Applied Chemistry
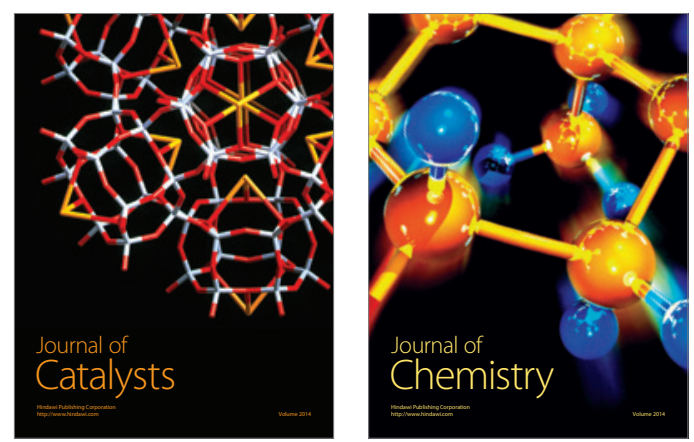
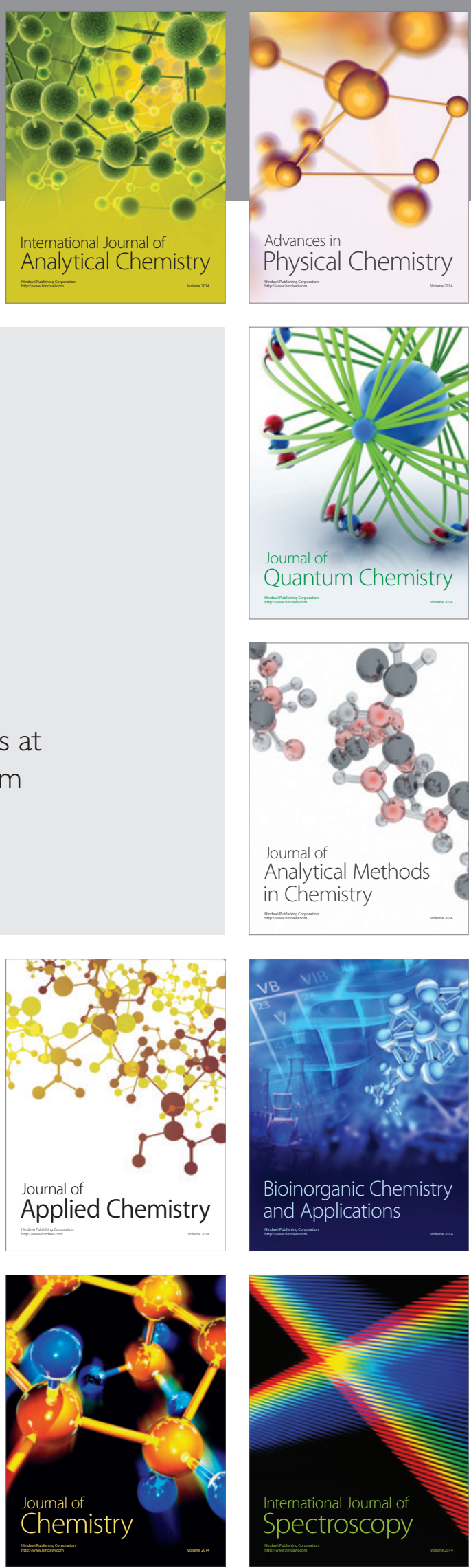